\title{
Analytical and Experimental Characterization of Gravity Induced Deformations In Subscale Gossamer Structures
}

\author{
John D. Johnston* \\ NASA Goddard Space Flight Center, Greenbelt, MD 20771 \\ Joseph R. Blandino ${ }^{\dagger}$ and Kiley C. McEvoy* \\ James Madison University, Harrisonburg, VA 22807
}

\begin{abstract}
The development of gossamer space structures such as solar sails and sunshields presents many challenges due to their large size and extreme flexibility. The post-deployment structural geometry exhibited during ground testing may significantly depart from the inspace configuration due to the presence of gravity-induced deformations (gravity sag) of lightly preloaded membranes. This paper describes a study carried out to characterize gravity sag in two subscale gossamer structures: a single quadrant from a $2 \mathrm{~m}, 4$ quadrant square solar sail and a $1.7 \mathrm{~m}$ membrane layer from a multi-layer sunshield. The behavior of the test articles was studied over a range of preloads and in several orientations with respect to gravity. An experimental study was carried out to measure the global surface profiles using photogrammetry, and nonlinear finite element analysis was used to predict the behavior of the test articles. Comparison of measured and predicted surface profiles shows that the finite element analysis qualitatively predicts deformed shapes comparable to those observed in the laboratory. Quantitatively, finite element analysis predictions for peak gravity-induced deformations in both test articles were within $10 \%$ of measured values. Results from this study provide increased insight into gravity sag behavior in gossamer structures, and demonstrates the potential to analytically predict gravity-induced deformations to within reasonable accuracy.
\end{abstract}

\section{Introduction}

$\mathrm{V}$ ery large, ultra-lightweight or 'gossamer' structures are an enabling technology for many future space missions. Figure 1 presents several examples of these thin-film membrane structures, including: solar sails, sunshields, antennas, and membrane optics. Solar sails provide propellantless propulsion by gaining momentum from solar photons. ${ }^{1}$ These structures require large reflective surface areas and will likely be among the largest and most lightweight of all gossamer structures in order to generate useful accelerations. A typical square solar sail structure consists of four triangular thin-film membrane quadrants supported by deployable booms. Deployable sunshields are utilized on large infrared space telescopes, such as the James Webb Space Telescope (JWST), to provide passive cooling for optics and instruments. Sunshield structures for such applications typically consist of multiple layers of thin-film membrane supported by deployable booms. ${ }^{2,3}$

The development of lightweight, deployable structures for solar sail and sunshield applications will be challenging due to strict requirements on mass, stowed volume, controlled deployment, film management, and postdeployment structural performance. Validated analytical models of these structures are required to accurately predict system level performance; however, their behavior can be highly nonlinear and difficult to predict. Ground testing is required to demonstrate deployment and post-deployment structural performance, as well as for validation of analytical models. Many of the challenges associated with pre-flight validation (e.g. ground testing) of gossamer structures are discussed in Ref. 4. The influence of the $1-\mathrm{g}$ environment presents one of the more significant challenges for ground testing of these structures. In many cases, some form of offloading will be required for deployment tests and the post-deployment structural geometry will depart from the in-space configuration

\footnotetext{
*Aerospace Engineer, Mechanical Systems Analysis and Simulation Branch (Code 542), AIAA Member.

+ Associate Professor, Integrated Science and Technology, MSC 4310, AIAA Senior Member.

¥ Undergraduate Research Assistant, Integrated Science and Technology, MSC 4310.
} 
significantly due to the presence of gravity induced deformations (gravity sag). In the case of both solar sails and sunshields, the deployed geometry of the thin-film membrantes neeed to be maintained in terms of both giobal shape and local surface flatness in order to meet mission requirements. Since ground tests will include gravity sag, it is important that analytical models take into account the influence of gravity when predicting structural performance. The in-space performance of the structures can then be predicted by analyses using the validated models with gravity effects removed.

The use of subscale structures is a common practice in the development of gossamer structures. Subscale structures are more easily tested and enable extrapolation to larger systems using scaling laws and validated models. The objective of this paper is to characterize the influence of gravity on the global geometry of two subscale gossamer test articles through a combination of analysis and experiment. The two structures to be studied are a 2.0 $\mathrm{m}$ solar sail and a $1.7 \mathrm{~m}$ sunshield. The test articles will be studied in both the horizontal and inclined orientations over a range of preloads. Brief descriptions of the test articles are provided in the following section. The analytical and experimental components of the study are then described. Finally, predicted and measured surface profiles are compared for both test articles. Results from this study will provide increased insight into gravity sag behavior in gossamer structures as well as current capabilities for analytically predicting this behavior.

\section{Subscale Gossamer Structures}

\section{A. Solar Sail Test Article}

The first test article, Fig. 2 , was $2 \mathrm{~m}$ representation of a single thin-film membrane quadrant from a 4 quadrant square sail. The overall geometry of the quadrant is triangular with maximum dimensions of $2.0 \mathrm{~m}$ wide by $1.0 \mathrm{~m}$ in height. The estimated mass of the test article is $38 \mathrm{~g}$. The coordinate system used in both the analysis and experiments is shown in Fig. 2. The origin is at the $90^{\circ}$ corner of the membrane with the xy plane in the plane of the membrane and the $z$ direction out-of-plane. The quadrant was fabricated from $2.54 \times 10-5 \mathrm{~m}$ thick Kapton film that is aluminized on one side. The membrane was attached to an aluminum support structure at three points using Kevlar threads. The connections were made at each of the corners of the triangular membrane. The corners of the membrane near the connections to the frame were reinforced using ultra high molecular weight (UHMW) polyethelene tape. The thread attached to the $90^{\circ}$ corner of the membrane was tied to the frame. The threads attached to the two $45^{\circ}$ corners were passed over pulleys with masses hung from the free ends to provide constant force preloading. Preloads of $0.69 \mathrm{~N}(70 \mathrm{~g}), 1.47 \mathrm{~N}(150 \mathrm{~g})$, and $2.16 \mathrm{~N}(220 \mathrm{~g})$ were applied to the membrane. The test frame was designed such that the side near the hypotenuse of the triangular quadrant was hinged. This allowed the test article to be inclined from $0^{\circ}$ (horizontal with gravity acting in the $-\mathrm{z}$ direction) to approximately $75^{\circ}$. Tests were completed at $0^{\circ}$ (horizontal) and $45^{\circ}$ orientations.

\section{B. Sunshield Test Article}

The second test article, Fig. 3, was a thin-film sunshield membrane layer used by the authors in a previous study ${ }^{5}$ to characterize the sunshield membrane geometry on both the global (shape) and local (wrinkling) scales. The test article geometry and support conditions are representative of an early concept for the JWST sunshield. ${ }^{6}$ The overall geometry of the membrane is diamond shaped with maximum dimensions of $1.7 \mathrm{~m}$ long by $0.7 \mathrm{~m}$ wide. The estimated mass of the test article is $25 \mathrm{~g}$. The coordinate system used in both the analysis and experiments is shown in Fig. 3. The origin is at the center of the membrane with the xy plane in the plane of the membrane and the $z$ direction out-of-plane. The test article was fabricated $2.54 \times 10-5 \mathrm{~m}$ thick Kapton film that was aluminized on one side. The membrane is supported at reinforced tabs (UHMW polyethelene tape) at the corners and at the center. Kevlar threads attached to the four corners apply the preloads and connect the membrane to the test support frame via delrin pass-throughs. Constant force preloads are applied by hanging proof masses from the ends of these threads. Preloads of $0.69 \mathrm{~N}(70 \mathrm{~g}), 1.47 \mathrm{~N}(150 \mathrm{~g})$, and $2.16 \mathrm{~N}(220 \mathrm{~g})$ were applied to the membrane. Additionally, the membrane is fixed in the center between two aluminum plates. These plates can be offset in the z-direction relative to the corners by adding a spacer (delrin block). In this study, the membrane was characterized in a configuration obtained by offsetting the center of the membrane $+0.012 \mathrm{~m}$ in the $\mathrm{z}$ direction. The angle between the central support and the corners due to the offsets is representative of the "v-groove" angles considered for the fullscale sunshield. The test frame is designed so that the membrane can be tested in a vertical or horizontal configuration. 


\section{Analysis}

Modeling and analysis of gossamer structures such as solar sails and sunshields is challenging due to the nonlinear behavior of the thin-film membrane layers that comprise an essential element of these structures. Examples of nonlinearities include large displacements that occur when the final global geometry is non-flat (due to gravity sag in ground tests, billowing of solar sails under the influence of solar photon pressure, or the development of "v-groove" angles between adjacent layers in multi-layer sunshield) and wrinkling. Significant progress has been made in the area of thin-film membrane analysis in recent years. ${ }^{7-16}$ The authors of this paper have previously used two approaches to predict the behavior of thin-film membrane structures. The first approach uses membrane elements in conjunction with tension field material models. ${ }^{5,9-11}$ This approach accounts for no-compression behavior associated with wrinkling and slackness, but does not predict wrinkle details. The second approach utilizes shell elements. ${ }^{5,12-15}$ Note that the shell approach can be used in conjunction with geometric imperfections seeded into the initial mesh that provides predictions for wrinkling details (amplitude, wavelength, \# of wrinkles). The shell element approach was used in this study to characterize gravity sag in subscale gossamer test structures. No attempt was made to model wrinkle details since the experimental study only characterized the global geometry of the test articles. The analyses were performed using ABAQUS finite element analysis software. ${ }^{17}$

\section{A. Solar Sail Analysis}

The sail quadrant finite element model is shown in Fig. 4. The mesh consists of 11895 nodes and 11645 elements. The thin-film membrane and corner reinforcements were modeled with shell elements. The film support strings were modeled using beam elements. Concentrated loads were applied to the ends of the stings to simulate the preloading in the tests. At the load application points, the model is fixed except in the loading direction. Nonlinear static analysis was performed to predict the stresses and displacements in the sail film due to preloading and gravity loading. Each analysis consisted of four steps: (1) apply $0.69 \mathrm{~N}$ preloads, (2) apply gravity loading, (3) Increase preload to $1.47 \mathrm{~N}$, and (4) Increase preload to $2.16 \mathrm{~N}$. Analysis was performed for two sail orientations: horizontal and 45 degrees to horizontal. The preloads were selected to provide average film stresses between $3.5 \mathrm{E} 4 \mathrm{~Pa} \mathrm{(5} \mathrm{psi)}$ and 1.1E5 $\mathrm{Pa}$ (15 psi) using the approach outlined in Ref. 18. This range of average film stresses is based on previous experience gained during ground testing of a subscale sunshield and has been suggested in other solar sail studies. ${ }^{19}$ Predictions from the sail analysis will be discussed in Section V: Comparison of Analysis and Experiment.

\section{B. Sunshield Analysis}

The finite element model of the sunshield layer is shown in Fig. 5. The same mesh consisting of 48545 Nodes and 47462 elements was used for all of the analyses. The thin-film membrane was modeled with shell elements. Each of the four comers has a reinforcement that is modeled using shell elements and an attached Kevlar thread that is modeled using beam elements. Loads were applied as concentrated forces at the ends of the Kevlar threads. This simulates the constant force preloading applied in the experiment. At the load application points, the model is fixed except in the loading direction. The aluminum plates that constrain the membrane at the center are modeled using C3D8 solid elements. The plates are constrained at four locations corresponding to where the plates are bolted to the test support frame. Nonlinear static analysis was performed to predict the stresses and displacements in the sunshield membrane due to preloading, enforced displacements, and gravity loading. Each analysis consisted of five steps: (1) apply $2.16 \mathrm{~N}$ preloads, (2) apply gravity loading, (3) offset center $+0.005 \mathrm{~m}$ in z direction, and (3) offset center $+0.012 \mathrm{~m}$ in z direction, (4) Reduce preload to $1.47 \mathrm{~N}$, and (5) Reduce preload to $0.69 \mathrm{~N}$. Analysis was performed for two sunshield orientations: horizontal and vertical. The preloads were selected based on previous subscale sunshield studies $^{9}$ to provide average film stresses on the order of $6.9 \mathrm{E} 4$ to $6.9 \mathrm{E} 3 \mathrm{~Pa}$ (10 to $100 \mathrm{psi}$ ). Predictions from the sunshield analysis will be discussed in Section V: Comparison of Analysis and Experiment.

\section{Experiments}

Photogrammetry has been employed previously to determine the 3-D surface profile of gossamer space structures. ${ }^{10-11,20}$ The surface profile (static shape) is found by accurately determining the location of targets in multiple images captured using calibrated cameras and triangulating. Since the two test articles used in this study have different support structures, the test set-ups were slightly different but the overall method is the same. Multiple cameras were used to capture images that were used to in a photogrammetric analysis to construct a 3-D profile of the structure. For this study four 5.0 megapixel cameras were used to capture images for analysis. Fixed retroreflective targets were used rather than dot projection photogrammetry. This is primarily due to the difficulties in mounting projectors above the test articles when they are in a horizontal configuration. There were approximately 130 targets on each test article arranged in a grid pattern (approximately $10 \times 10 \mathrm{~cm}$ for the sail quadrant and $8 \times 10$ 
$\mathrm{cm}$ for the sunshield). The grid patterns for the two test articles can be seen in Figs. 2 and 3. The number of targets was sufficient to capture the global surface profile of the test articles, but not the local wrinkling details. Because of their small size the targets added minimal mass $(0.004 \mathrm{~g} / \mathrm{target})$ to the test articles. Note that the total mass of the targets $(0.5 \mathrm{~g})$ represents approximately $1 \%$ of the total mass of the solar sail quadrant and $2 \%$ of the mass of the sunshield layer. The targets do add some local stiffness to the membrane. This stiffness will affect local details, such as wrinkling, but does not affect the global shape of the membrane. The retro-reflective targets were illuminated using the standard camera flash. The image scale was determined using retro-reflective "scale tape" that was attached to the test frames. This tape is black with retro-reflective targets evenly spaced along the length. Both test articles were studied in horizontal $\left(0^{\circ}\right)$ and inclined positions. The $2 \mathrm{~m}$ sail quadrant was supported both horizontally and inclined at $45^{\circ}$. The sunshield was tested in horizontal and vertical $\left(90^{\circ}\right)$ configurations. Results from both the solar sail and sunshield experiments will be discussed in Section V: Comparison of Analysis and Experiment.

Because the accuracy of optical measurement techniques such as photogrammetry vary depending on the application it was necessary to evaluate the accuracy of the measurement system. The best method to evaluate accuracy is to have targets at known coordinates distributed throughout the image. This was not possible for this study. Instead we chose to evaluate the accuracy by measuring targets of known spacing. To do this retro-reflective targets we placed on the sides of each test frame using a scale tape designed and manufactured for use in photogrammetry applications. The tape used for the sunshield had $12.7 \mathrm{~mm}$ dia. targets spaced every $101.6 \mathrm{~mm}$. For the $2 \mathrm{~m}$ sail quadrant a tape with $3 \mathrm{~mm}$ dia. targets spaced every $25.4 \mathrm{~mm}$ was used. The tape manufacturer claims a tolerance on the target spacing of $+/-0.0254 \mathrm{~mm}$. The tape can be seen on the support frames shown in figs 2 and 3 . The distance between adjacent targets on the frame was determined from Equation (1).

$$
L_{i j}=\left\lfloor\left(x_{j}-x_{i}\right)+\left(y_{j}-y_{i}\right)^{2}+\left(z_{j}-z_{i}\right)^{2}\right\rfloor
$$

Although all the targets used to asses accuracy were positioned close to the xy plane they allow errors in the $\mathrm{x}$ and $y$ positions to be quantified (note that there is some variation in $z$ measurements due to manufacturing imperfections, or slight bowing, of the aluminum extrusions used for the test frames). If the spacing ( $x$ and $y$ positions) are found to within 1.0 pixel then the out of plane coordinates determined from the analysis can be considered reliable. For both test articles the images covered approximately $2 \mathrm{~m}$. The cameras capture an image 2560 x 1920 pixels. Therefore each pixel is approximately $0.8 \mathrm{~mm}$. The target spacing for the sunshield in the horizontal position and the sail quadrant in both the horizontal and inclined position were used to evaluate the target spacing. Table 1 gives the nominal and average target spacing determined using photogrammetry. The table also gives the tolerance using a 95\% confidence (two standard deviations). Table 1 shows that for the sail quadrant in both configurations the average target spacing and the nominal target spacing are essentially identical. For the sunshield the nominal value is within the tolerance of the measurement. In all cases the measurement tolerance is within 0.2 $\mathrm{mm}$. Recall that one pixel was $0.8 \mathrm{~mm}$. Therefore the marking accuracy for the $\mathrm{x}$ and $\mathrm{y}$ coordinates is better than 0.25 pixels. Based on experience, from the $x$ and $y$ accuracy values we can infer that the $z$ accuracy will be within $0.3 \mathrm{~mm}$.

Table 1. Evaluation of targets of known spacing.

\begin{tabular}{lccc}
\hline & Sunshield Horizontal & Sail Quadrant $0^{\circ}$ Incline & Sail Quadrant $45^{\circ}$ Incline \\
\hline Nominal Spacing $(\mathrm{mm})$ & $101.6+/-0.0254$ & $25.4+/-0.0254$ & $25.4+/-0.0254$ \\
Average Spacing $(\mathrm{mm})$ & 101.5625 & 25.40676 & 25.40505 \\
Tolerance (2 std. dev) & 0.19399 & 0.12817 & 0.14181 \\
\# of Target Pairs & 18 & 177 & 188 \\
\hline
\end{tabular}

To evaluate the repeatability of the measurement system and to determine if the sail quadrant changed over time, data was collected for two tests approximately 18 days apart. Data for the targets along the centerline of the membrane (apex to center of hypotenuse) were compared for the $0.69 \mathrm{~N}$ and $2.16 \mathrm{~N}$ test cases. For the $0.69 \mathrm{~N}$ case there is good agreement between the two tests from the apex to approximately the center of the membrane. From the center of the membrane to the hypotenuse the error increases steadily. This same trend is shown for the $2.16 \mathrm{~N}$ case. From the apex to the center of the membrane the difference between the two tests is less than $1 \mathrm{~mm}$. The difference between tests increase steadily from the center to the free edge at the center of the hypotenuse. For both load cases the maximum difference between experiments is approximately $3 \mathrm{~mm}$. Although this is relatively small compared to the absolute displacements the trend and its location in a relatively slack region of the membrane warrants further investigation. 


\section{Comparison of Analysis and Experiment}

Measured and predicted surface profiles for the solar sail and sunshield test articles are compared in this section.

\section{A. Solar Sail}

The surface profile of the solar sail test article was characterized for three preload levels $(0.69 \mathrm{~N}, 1.47 \mathrm{~N}$, and $2.16 \mathrm{~N}$ ) and in two orientations with respect to gravity (horizontal with gravity in the $-\mathrm{z}$ direction and 45 degrees to horizontal). In all loading cases and for both tests and finite element analysis (FEA), the global surface profile involves a 'billowing' of the sail quadrant in the $-z$ direction. Maximum $z$ displacements occur at the mid-point of the $+y$ edge of the membrane. This global surface profile is illustrated in Fig. 6 which presents surface plots overlaid with contour plots of z-displacement for a $0.69 \mathrm{~N}$ preload and a horizontal orientation from both test and analysis. Comparisons of analysis and experiment for the solar sail quadrant are presented graphically in Fig. 6-9 and numerically in Tables 2-3. Figures 7-8 compare measured and predicted contour plots of z-displacement at each preload level for the horizontal and 45 degree orientations, respectively. Examination of the contour plots shows that, as expected, the 'sagging' of the sail quadrant decreases with increasing preload. Based on the test data, a factor of 3 increase in preload resulted in a factor of 2.5 decrease in peak sag along the outer edge. Note that the gravity sag deformations in the $\mathbf{4 5}$ degree orientation are reduced compared to those in the horizontal orientation. In some instances it may be advantageous to orient gossamer structures such that the effect of gravity loads is predominantly in the plane of the membrane, thereby reducing gravity induced out-of-plane deformations.

A detailed comparison of out-of-plane displacements along the edges and centerline of the quadrant is presented in Fig. 9. Along the line of constant $x=0$ (centerline), Fig. 9a, the test results and finite element analysis (FEA) predictions show excellent agreement up until $y=0.5 \mathrm{~m}$, but from this point out to the $+y$ edge the measured results exceed predictions. Note that the test-to-test deviations noted in the experimental repeatability discussion exhibited a similar trend, but with smaller deviations than between test and FEA. This deviation is illustrated more clearly in Fig. $9 \mathrm{~b}$ which provides a plot of the $\mathrm{z}$-displacement as a function of $\mathrm{x}$ along the $+\mathrm{y}$ edge. Measured values exceed the FEA predictions along this line. Peak sag is seen in the $0.69 \mathrm{~N}$ preload/horizontal orientation load case at $(x=0$ $\mathrm{m}, \mathrm{y}=1 \mathrm{~m}$ ) where the measured $\mathrm{z}$-displacement is $-0.189 \mathrm{~m}$ and the predicted value is $-0.169 \mathrm{~m}$ (difference of 0.019 $\mathrm{m}$ or $10 \%$ ). The $\mathrm{z}$-displacements along the $+\mathrm{x}$ edge of the membrane are shown in Fig. 9c. Along this edge the FEA predictions typically exceed the measured values. The correlation between test and FEA is better along the $+x$ edge than along the $+y$ edge with excellent agreement for the 45 degree orientation.

Tables 2 and 3 provide a quantitative comparison of results from test and FEA at four points on the sail. Point 1 at $(x=0, y=1)$, corresponding to the location exhibiting maximum $z$-displacement, shows has an average $\%$ difference across all preloads of $17 \%$ for both orientations. Point 2 at $(x=0, y=0.5)$ has an average $\%$ difference across all preloads of $2 \%$ for the horizontal case and $8 \%$ for the 45 degree case. Points 3 and 4 at $(x=0.5, y=+1-0.5)$ have an average $\%$ difference across all preloads of $24 \%$ for the horizontal case and $3 \%$ for the 45 degree case. In general, the average $\%$ test/FEA difference across all preloads and locations is $17 \%$ for the horizontal orientation and $8 \%$ for the 45 degree orientation. Another way of comparing the results is to consider the root-mean-square (RMS) of the difference between test and FEA values. The RMS difference is $0.011 \mathrm{~m}$ for the horizontal case and $0.007 \mathrm{~m}$ for the 45 degree case. These differences are well above the estimated accuracy $(0.0003 \mathrm{~m})$ of the $\mathrm{z}$ measurements, but within a factor of four of the estimated measurement repeatability $(0.003 \mathrm{~m})$. Comparing the RMS values to the length scale of the test article $(2 \mathrm{~m})$ shows that the differences are less than $1 \%$ of the length scale for both cases.

Table 2: Measured and predicted $\mathrm{z}$ displacements for key locations on solar sail in horizontal orientation.

\begin{tabular}{|c|c|c|c|c|c|c|c|c|c|c|c|}
\hline \multirow{2}{*}{\multicolumn{3}{|c|}{ Orientation = Horizontal }} & \multicolumn{3}{|c|}{ Preload $=0.69 \mathrm{~N}(70 \mathrm{~g})$} & \multicolumn{3}{|c|}{ Prelosd $=1.47 \mathrm{~N}(150 \mathrm{~g})$} & \multicolumn{3}{|c|}{ Preload $=2.16 \mathrm{~N}(220 \mathrm{~g})$} \\
\hline & & & Test & FEA & Difference & Test & FEA & Difference & Test & FEA & Difference \\
\hline Point & $x(m)$ & $y(m)$ & $z(m)$ & $z(m)$ & $d z(m)$ & $z(m)$ & $2(m)$ & $d z(m)$ & $z(m)$ & $z(m)$ & $\mathrm{dz}(\mathrm{m})$ \\
\hline 1 & 0.000 & 1.000 & -0.189 & -0.169 & -0.019 & -0.100 & -0.084 & -0.016 & -0.077 & -0.058 & -0.019 \\
\hline 2 & 0.000 & 0.500 & -0.112 & -0.112 & -0.001 & -0.054 & -0.054 & 0.000 & -0.039 & -0.037 & -0.002 \\
\hline 3 & 0.500 & 0.500 & -0.074 & -0.089 & 0.015 & -0.031 & -0.041 & 0.010 & -0.023 & -0.028 & 0.004 \\
\hline 4 & -0.500 & 0.500 & -0.081 & -0.089 & 0.008 & -0.031 & -0.041 & 0.010 & -0.021 & -0.028 & 0.007 \\
\hline
\end{tabular}

Table 3: Measured and predicted z displacements for key locations on solar sail in 45 degrees orientation.

\begin{tabular}{|c|c|c|c|c|c|c|c|c|c|c|c|}
\hline \multirow{2}{*}{\multicolumn{3}{|c|}{$\begin{array}{c}\text { Orientation }=45 \text { Degrees to } \\
\text { Horizontal }\end{array}$}} & \multicolumn{3}{|c|}{ Preload $=0.69 \mathrm{~N}(70 \mathrm{~g})$} & \multicolumn{3}{|c|}{ Preload $=1.47 \mathrm{~N}(150 \mathrm{~g})$} & \multicolumn{3}{|c|}{ Preload $=2.16 \mathrm{~N}(220 \mathrm{~g})$} \\
\hline & & & Test & FEA & Difference & Test & FEA & Difference & Test & FEA & Difference \\
\hline Point & $x(m)$ & $y(m)$ & $z(m)$ & $z(m)$ & $\mathrm{dz}(\mathrm{m})$ & $z(m)$ & $z(m)$ & $\mathrm{d} z(\mathrm{~m})$ & $z(m)$ & $z(m)$ & $d z(m)$ \\
\hline 1 & 0.000 & 1.000 & -0.133 & -0.119 & -0.013 & -0.072 & -0.060 & -0.012 & -0.055 & -0.041 & -0.013 \\
\hline 2 & 0.000 & 0.500 & -0.074 & -0.069 & -0.005 & -0.039 & -0.036 & -0.003 & -0.028 & -0.025 & -0.003 \\
\hline 3 & 0.500 & 0.500 & -0.048 & -0.049 & 0.001 & -0.025 & -0.025 & -0.001 & -0.019 & -0.018 & -0.002 \\
\hline 4 & -0.500 & 0.500 & -0.048 & -0.049 & 0.001 & -0.025 & -0.025 & 0.000 & -0.019 & -0.018 & -0.001 \\
\hline
\end{tabular}




\section{B. Sunshield}

The surface profile of the sunshield test anticle was characterized for three preioad leveis $(0.69 \mathrm{~N}, 1.47 \mathrm{~N}$, and $2.16 \mathrm{~N}$ ) and in two orientations with respect to gravity (vertical with gravity acting in the $-\mathrm{y}$ direction and horizontal with gravity acting in the $-z$ direction). The global surface profile in the vertical orientation consists of a tent-like shape. This is illustrated in Fig. 10 which presents surface plots overlaid with contour plots of z-displacement for a $0.69 \mathrm{~N}$ preload and a vertical orientation from both test and analysis. The measured and predicted global surface profiles in the vertical orientation showed negligible changes as a function of preload. This is an advantageous orientation in which to test the sunshield since gravity loads are minimized in the out-of-plane direction. In fact, the vertical global surface profile predicted by FEA shows only minor differences with and without gravity loads. Since gravity-induced deformations were deemed not significant for this orientation, it was not considered in further detail. The global surface profile of the membrane in the horizontal orientation also features a tent-like shape, but departs considerably from the vertical profile in that it exhibits significant sagging of the outer edges in the $-z$ direction due to the out-of-plane gravity load. This surface profile is illustrated in Fig. 11 which presents surface plots overlaid with contour plots of z-displacement for a $0.69 \mathrm{~N}$ preload from both test and analysis. Comparisons of analysis and experiment for the sunshield in the horizontal orientation are presented graphically in Fig. 11-13 and numerically in Table 4 for a range of preloads. Figure 12 compares measured and predicted contour plots of z-displacement at each preload level. The results illustrate that, as expected, the 'sagging' of the sunshield decreases with increasing preload. Based on the test data, a factor of 3 increase in preload resulted in a factor of two decrease in peak sag.

A detailed comparison of $z$ displacements along several 'cuts' across the membrane is presented in Fig. 13. Along the line of constant $x=0 \mathrm{~m}$, Fig. 13a, the test results and finite element analysis (FEA) predictions show the same general trends and exhibit fair agreement with measured results exceeding analytical prediction predictions. Along the line of constant $y=+0.3 \mathrm{~m}$, Fig. 13b, the test results and FEA predictions show excellent agreement. The FEA values exceed the measured values at the peaks (near $x=0 \mathrm{~m}$ ). Inspection of the photograph of the test article in Fig. 3 shows that the membrane has a large wrinkle along the $y$-axis that is captured by the FEA, but missed by the photogrammetry due to the location of targets on either side of the wrinkle peak. Similarly, along the line of constant $y=-0.4 \mathrm{~m}$, Fig. 13c, test and FEA values show good agreement.

Table 4 presents a quantitative comparison of results from test and FEA at eight points on the sunshield. Points 1 and 3, corresponding to the locations exhibiting peak $z$-displacement on the $+y$ side of the membrane, show an average difference of $8 \%$ for the $0.69 \mathrm{~N}$ preload. At these points, differences between test and FEA for the higher preloads are similar to the absolute displacements (on the order of millimeters). Points 6 and 8 correspond to the locations exhibiting peak z-displacement on the $-y$ side of the membrane. Peak sag is seen at these points for the $0.69 \mathrm{~N}$ preload case where the average measured $\mathrm{z}$-displacement is $-0.018 \mathrm{~m}$ and the predicted value is $-0.019 \mathrm{~m}$ (difference of $0.001 \mathrm{~m}$ or $5 \%$ ). The test results exhibit some asymmetry about the $y$-axis which is comparable to the test/FEA differences at the $2.16 \mathrm{~N}$ preload level. Differences between test and FEA are negligible at point 8 across all preloads. The RMS difference between the test and FEA values is $0.002 \mathrm{~m}$ for each load case. This is less than $1 \%$ of the length scale (taken as the average of the length and width dimensions=1.2 $\mathrm{m}$ ) for the test article.

Table 4: Measured and predicted $\mathrm{z}$ displacements for key locations on sunshield in horizontal orientation.

\begin{tabular}{|c|c|c|c|c|c|c|c|c|c|c|c|}
\hline \multirow{2}{*}{\multicolumn{3}{|c|}{ Orientation = Horizontal }} & \multicolumn{3}{|c|}{ Preload $=0.69 \mathrm{~N}(70 \mathrm{~g})$} & \multicolumn{3}{|c|}{ Preload $=1.47 \mathrm{~N}(150 \mathrm{~g})$} & \multicolumn{3}{|c|}{ Preload $=2.16 \mathrm{~N}(220 \mathrm{~g})$} \\
\hline & & & Test & FEA & Difference & Test & FEA & Difference & Test & FEA & Difference \\
\hline Point & $x(m)$ & $y(m)$ & $z(m)$ & $z(m)$ & $d z(m)$ & $z(m)$ & $z(m)$ & $d z(m)$ & $z(m)$ & $z(m)$ & 由 $(m)$ \\
\hline 1 & -0.200 & 0.300 & -0.012 & -0.013 & 0.001 & -0.005 & -0.007 & 0.002 & -0.003 & -0.005 & 0.002 \\
\hline 2 & 0.000 & 0.300 & -0.001 & 0.004 & -0.005 & 0.003 & 0.006 & -0.003 & 0.005 & 0.007 & -0.002 \\
\hline 3 & 0.200 & 0.300 & -0.012 & -0.013 & 0.001 & -0.006 & -0.007 & 0.001 & -0.004 & -0.005 & 0.001 \\
\hline 4 & 0.200 & 0.000 & 0.003 & 0.005 & -0.002 & 0.005 & 0.007 & -0.002 & 0.006 & 0.007 & -0.001 \\
\hline 5 & -0.200 & 0.000 & 0.003 & 0.005 & -0.002 & 0.005 & 0.007 & -0.002 & 0.006 & 0.007 & -0.001 \\
\hline 6 & -0.200 & -0.400 & -0.017 & -0.019 & 0.002 & -0.007 & -0.011 & 0.004 & -0.006 & -0.009 & 0.003 \\
\hline 7 & 0.000 & -0.400 & -0.006 & -0.003 & -0.003 & 0.002 & 0.004 & -0.002 & 0.002 & 0.005 & -0.003 \\
\hline 8 & 0.200 & -0.400 & -0.019 & -0.019 & 0.000 & -0.011 & -0.012 & 0.001 & -0.009 & -0.009 & 0.000 \\
\hline
\end{tabular}

\section{Conclusions}

A detailed comparison of experimental measurements and finite element analysis predictions for gravity-induced deformations, or gravity sag, has been presented for two subscale gossamer test structures: a $2 \mathrm{~m}$ solar sail quadrant and a $1.7 \mathrm{~m}$ sunshield membrane layer. The comparison of measured and predicted surface profiles shows that finite element analysis qualitatively predicts the same deformed shapes as were observed in the laboratory. Quantitatively, finite element analysis predictions for peak gravity-induced deformations in both test articles were within $10 \%$ of measured values. The RMS difference between test and analysis was $0.009 \mathrm{~m}$ (average of two orientations) for the solar sail and $0.002 \mathrm{~m}$ for the sunshield which represents less than $1 \%$ of the overall length scales of the test articles. 
While this study has demonstrated the potential to analytically predict gravity-induced deformations in gossamer structures to within reasonabie accuracy, improved correiation is desirable. Note that since the focus of the study was on global shape, the present analysis utilized general purpose shell elements and ignored effects such as wrinkling. Improved correlation could potentially be obtained by employing more advanced analytical approaches ${ }^{5}$ that have previously been employed to study membrane surface profiles on both the global and local scales. Several general observations were made regarding gravity-induced deformations. First, it was observed that as expected increasing the membrane preload reduces the gravity-induced deformations. For example, increasing the preload in the solar sail by a factor of three (increasing the nominal membrane stress from approximately 5 to 15 psi) reduced the measured peak sag by a factor of 2.5. While it may be advantageous to decrease gravity sag so that ground and on-orbit geometries are similar, achieving this through preload increases results higher membrane stresses as well as corresponding increases in compressive loading on support booms. Second, it was observed that orienting test articles to minimize gravity loads acting in the out-of-plane direction for thin-film membranes could reduce gravityinduced deformations. Thus, in some cases it may possible to complete ground testing in an orientation that minimizes gravity sag and produces a deployed geometry similar to the on-orbit $(0-\mathrm{g})$ configuration.

\section{References}

1. Salama, M., McInnes, C., and Mulligan, P., "Gossamer Sailcraft Technology," Gossamer Spacecraft: Membrane and Inflatable Structures Technology for Space Applications, Progress in Astronautics and Aeronautics, Volume 191, Edited by Christopher M. Jenkins, 2000.

2. Perrygo, C., Choi, M., Parrish, K., Schunk, G., Stanley, D., and Wooldridge, E. "Passive Thermal control of the NGST," Space Telescopes and Instruments V, Proc. SPIE 3356, 1102-1113, 1998.

3. Johnston, J., Ross, B., Blandino, J., Lawrence, J., and Perrygo, C., "Development of Sunshield Structures for Large Space Telescopes," Proceedings of the 2002 SPIE Astronomical Telescopes and Instrumentation Meeting, Kona, HI, August 2002.

4. Wada, B. and Lou, M., "Pre-Flight Validation of Gossamer Structures," $44^{\text {th }}$ AIAA Structures, Structural Dynamics, and Materials Conference, April 7-10, 2003, AIAA-2003-1373.

5. Johnston, J., Blandino, J., Black, J., and Pappa, R., "Structural Analysis and Testing of a Subscale Sunshield Membrane Layer," 44 ${ }^{\text {th }}$ AIAA Structures, Structural Dynamics, and Materials Conference, April 7-10, 2003, AIAA-2003-1742.

6. Bely, P.Y., Perrygo, C. and Burg, R., “NGST Yardstick Mission,"NGST Monograph No. 1, July 1999.

7. Adler, A.L., Mikulas, M.M., and Hedgepeth, J.M., "Static and Dynamic Analysis of Partially Wrinkled Membrane Structures," $41^{\text {st }}$ AIAA Structures, Structural Dynamics, and Materials Conference, Atlanta, GA, April 2000, AIAA-20001810.

8. Johnston, J. and Lienard, S., "Modeling and Analysis of Structural Dynamics for a One-Tenth Scale Model NGST Sunshield", $42^{\text {nd }}$ Structures, Structural Dynamics, and Materials Conference, Seattle, WA, April 16-19, 2001, AIAA-20011407.

9. Johnston, J. "Finite Element Analysis of Wrinkled Membrane Structures for Sunshield Applications," 43 ${ }^{\text {rd }}$ AIAA Structures, Structural Dynamics, and Materials Conference, Denver, CO, April 22-25, 2002, AIAA-2002-1456.

10. Blandino, J.R., Johnston, J.D., and Dharamsi, U.K., "Comer Wrinkling of a Square Membrane Due to Symmetric Mechanical Loads," Journal of Spacecraft and Rockets, Vol. 39, No. 5, September-October 2002, pp. 717-724.

11. Blandino, J.R., Johnston, J.D., Miles, J.J., Dharamsi, U.K., "The Effect of Asymmetric Mechanical and Thermal Loading on Membrane Wrinkling," AIAA Paper 2002-1371, 43 ${ }^{\text {rd }}$ AIAA Structures, Structural Dynamics and Materials Conference, April 22-25, 2002, Denver, CO.

12. Lee, K. and Lee, S., "Analysis of Gossamer Space Structures Using Assumed Strain Formulation Solid Shell Elements," $43^{\text {rd }}$ AIAA Structures, Structural Dynamics, and Materials Conference, Denver, CO, April 22-25, 2002, AIAA-2002-1559.

13. Wong, Y.W. and Pellegrino, S., "Prediction of Wrinkle Amplitudes in Square Solar Sails," 44 $4^{\text {th }}$ AIAA Structures, Structural Dynamics, and Materials Conference, April 7-10, 2003, AIAA-2003-1982.

14. Kukathasan, S. and Pellegrino, S., "Nonlinear Vibration of Wrinkled Membranes," $44^{\text {th }}$ AIAA Structures, Structural Dynamics, and Materials Conference, April 7-10, 2003, AIAA-2003-1747.

15. Tessler, A., Sleight, D., and Wang, J., "Nonlinear Shell Modeling of Thin Membranes With Emphasis on Structural Wrinkling," 44 $4^{\text {th }}$ AIAA Structures, Structural Dynamics, and Materials Conference, April 7-10, 2003, AIAA-2003-1931.

16. Johnston, J. and Parrish, K., "Thermal-Structural Analysis of Sunshield Membranes," $44^{\text {th }}$ AIAA Structures, Structural Dynamics, and Materials Conference, Norfolk, VA, April 7-10, 2003, AIAA-2003-1904.

17. ABAQUS/Standard User's Manual, Version 6.4, Pawtucket, RI, 2003.

18. Greschik, G., Murphey, T, Mikulas, M., and Belvin, K., "A Rule of Thumb for the Suspension of Film Sheets Without Catenaries," $44^{\text {th }}$ AIAA Structures, Structural Dynamics, and Materials Conference, Norfolk, VA, April 7-10, 2003, AIAA2003-1907.

19. Mikulas, M and Adler, A., "Rapid Structural Assessment Approach for Square Solar Sails Including Edge Support Cables," $44^{\text {th }}$ AIAA Structures, Structural Dynamics, and Materials Conference, Norfolk, VA, April 7-10, 2003, AIAA-2003-1447.

20. Pappa, R., Jones, T., Black, J., Walford, A., Robson, S., and Shortis, M., "Photogrammetry Methodology Development for Gossamer Spacecraft Structures," NASA TM-2002-211739, June 2002. 


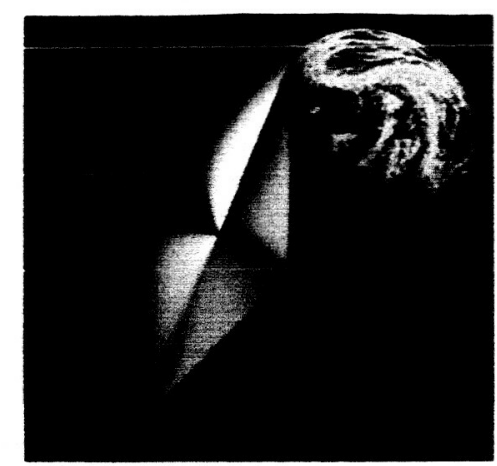

Solar Sail

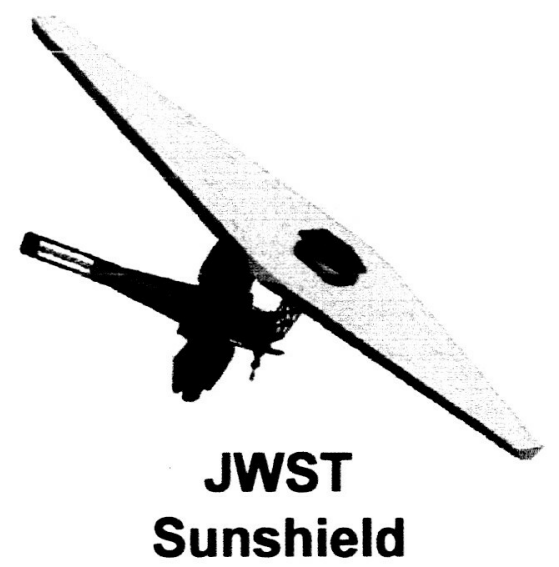

Figure 1: Conceptual designs for future gossamer space structures.
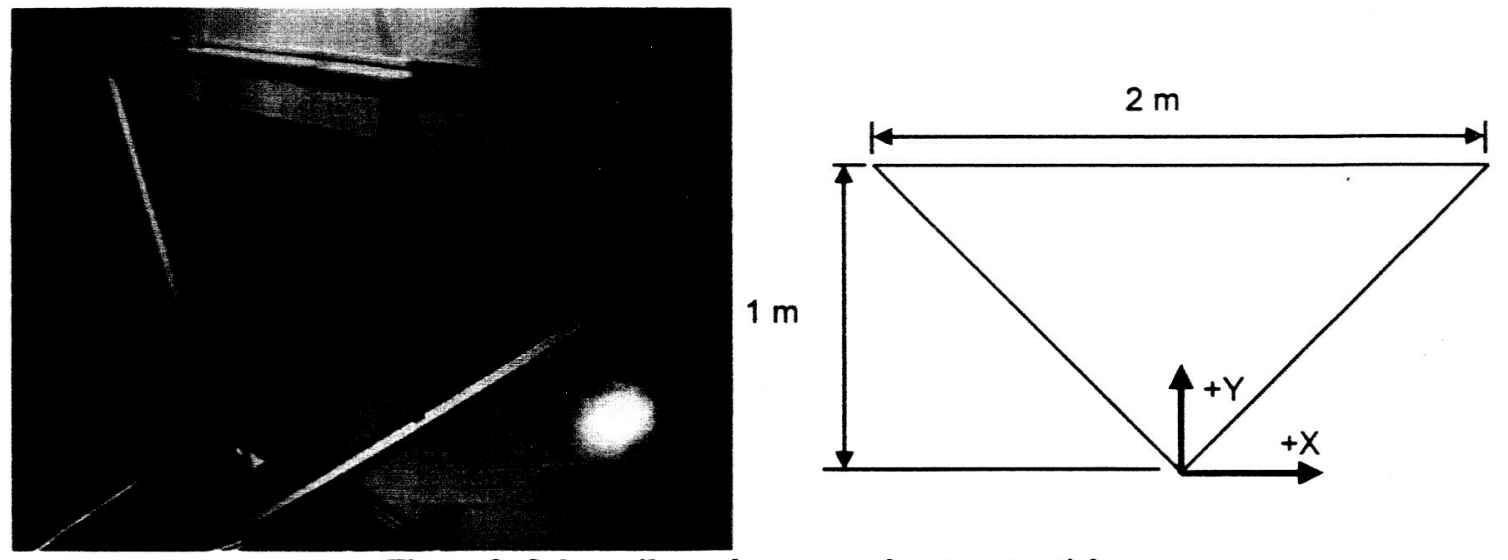

Figure 2: Solar sail membrane quadrant test article.
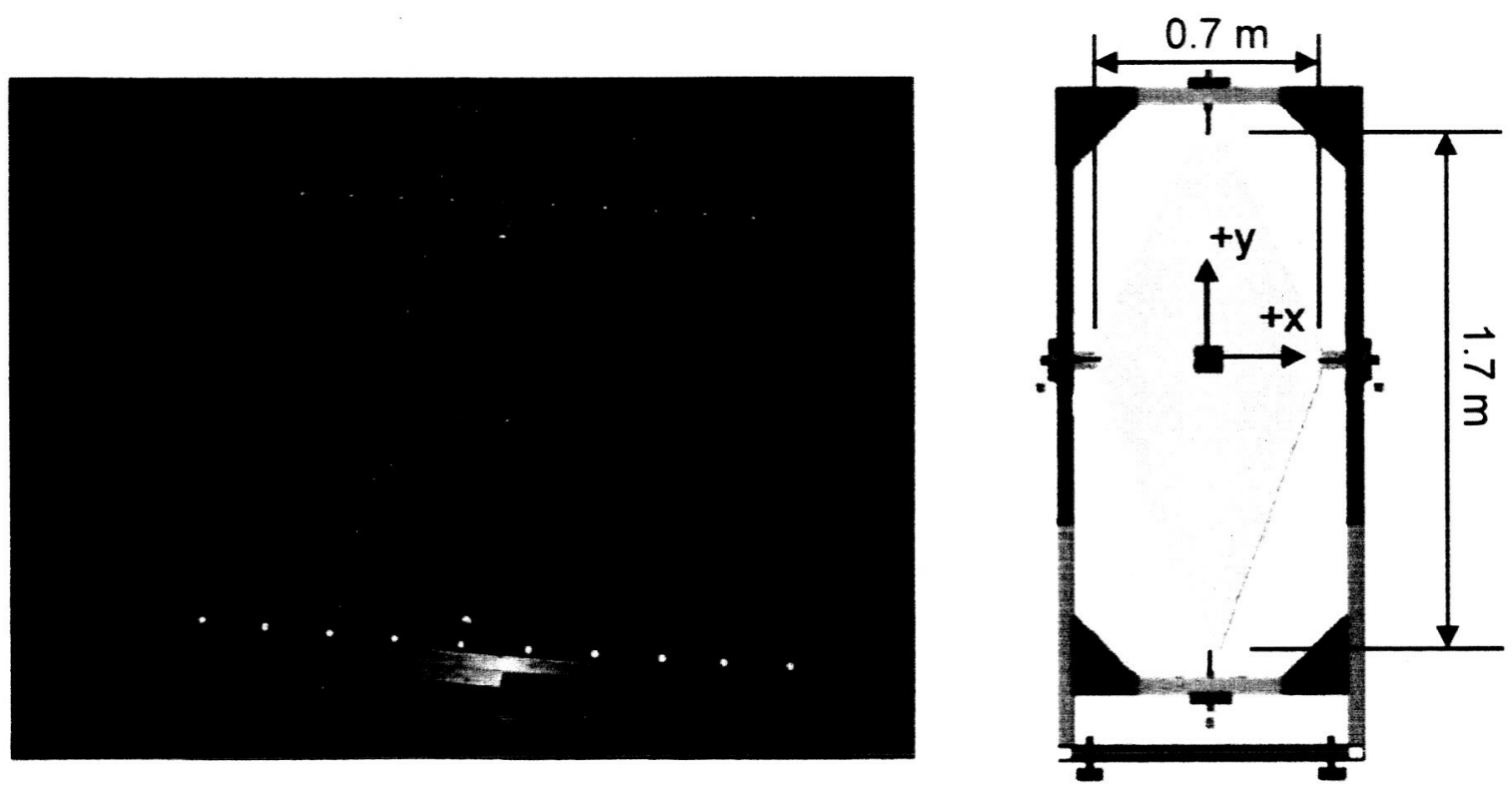

Figure 3: Sunshield single membrane layer test article. 

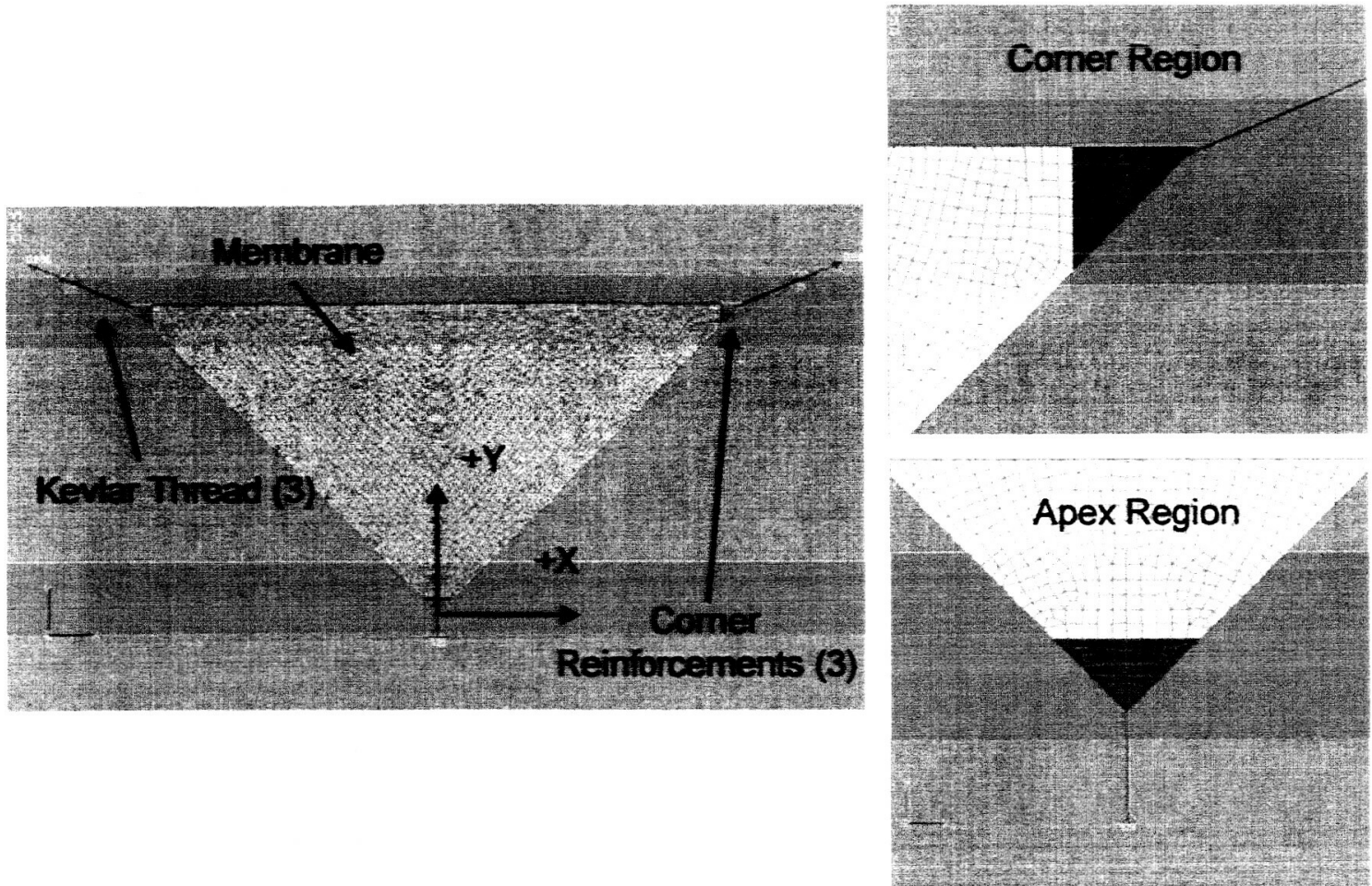

Figure 4: Finite element model of solar sail quadrant.
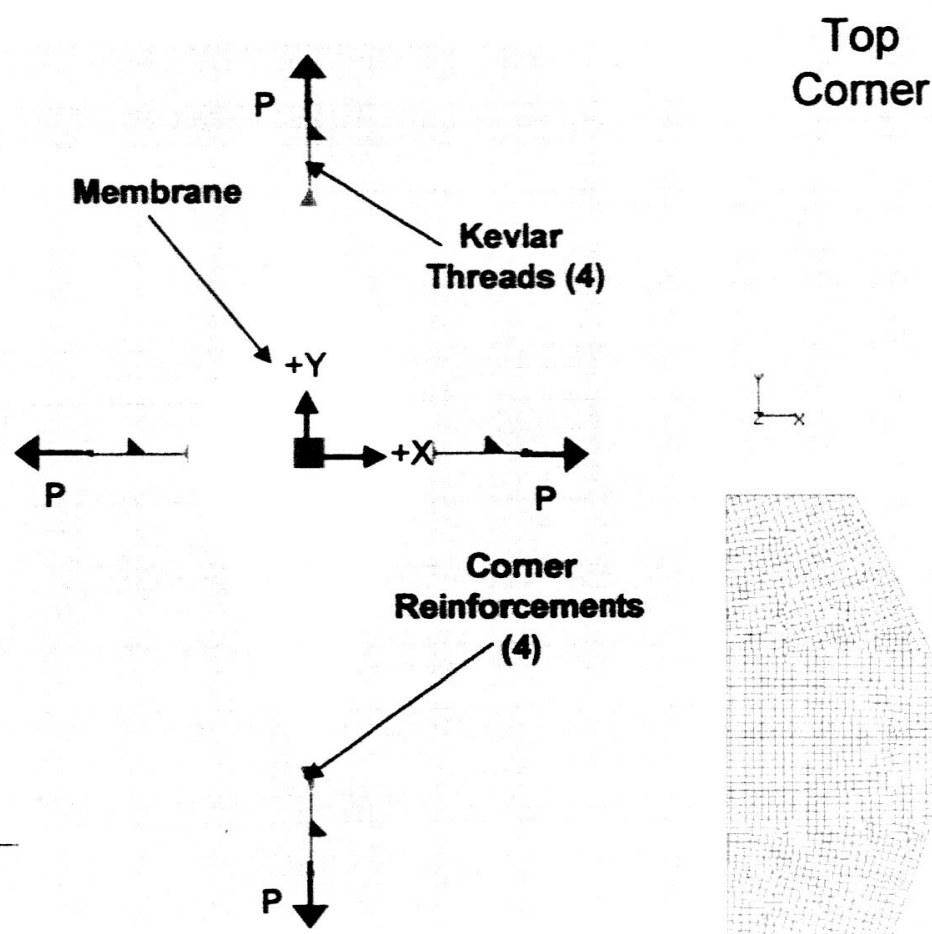

Right-Side Corner

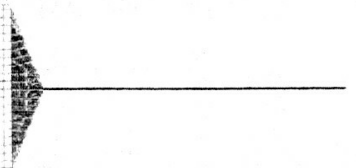

Figure 5: Finite element model of sunshield membrane layer. 

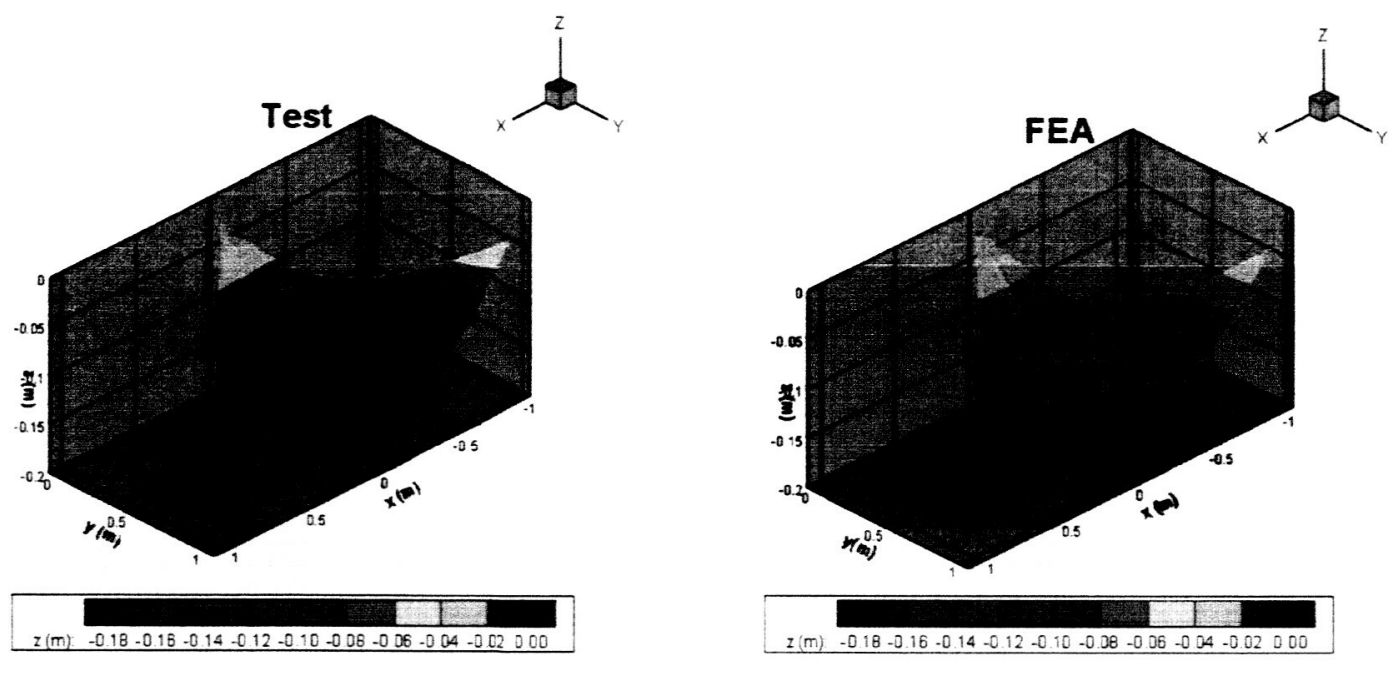

\section{Test}

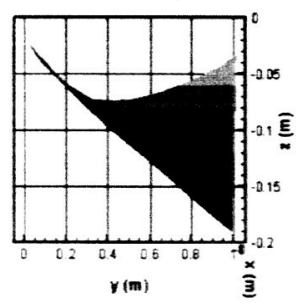

$z(m)-0.18-0.16-014-012-010-008-006-0.04-002000$

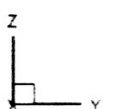

FEA
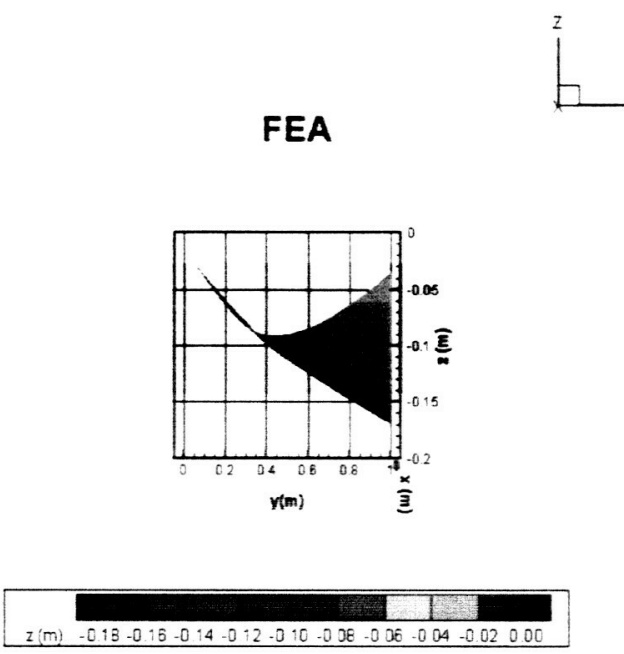

Figure 6: Comparison of measured (Test) and predicted (FEA) surface profiles for solar sail quadrant orientated horizontally under $0.69 \mathrm{~N}(70 \mathrm{~g})$ preload. 

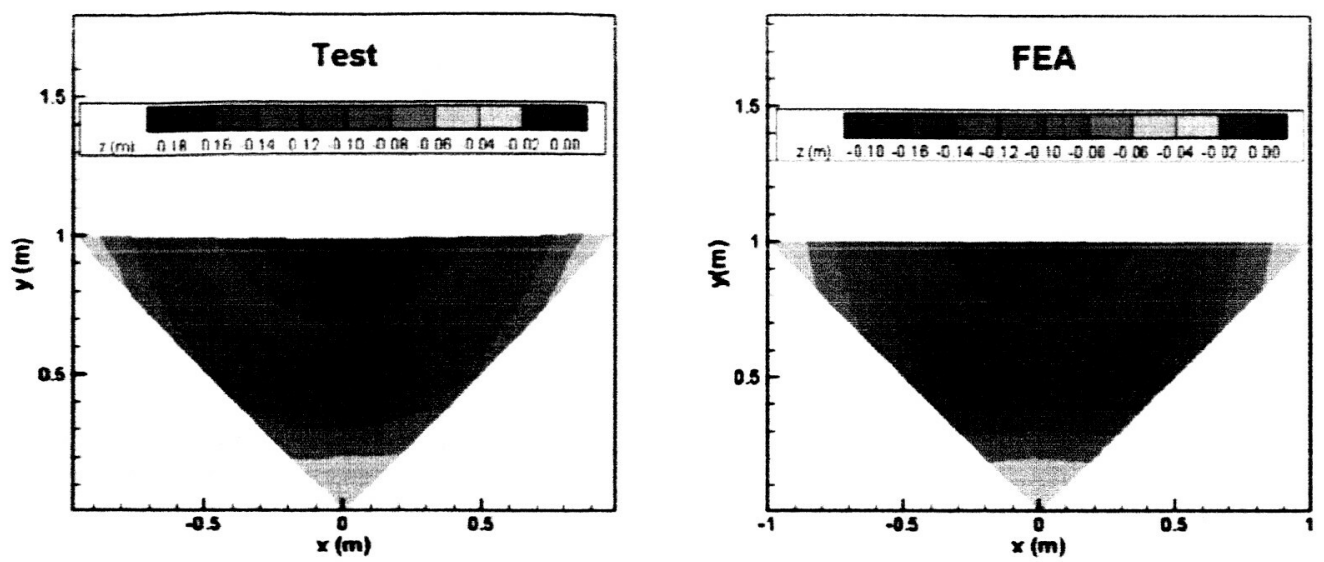

(a) Corner preload $=0.69 \mathrm{~N}$ (70 g masses)
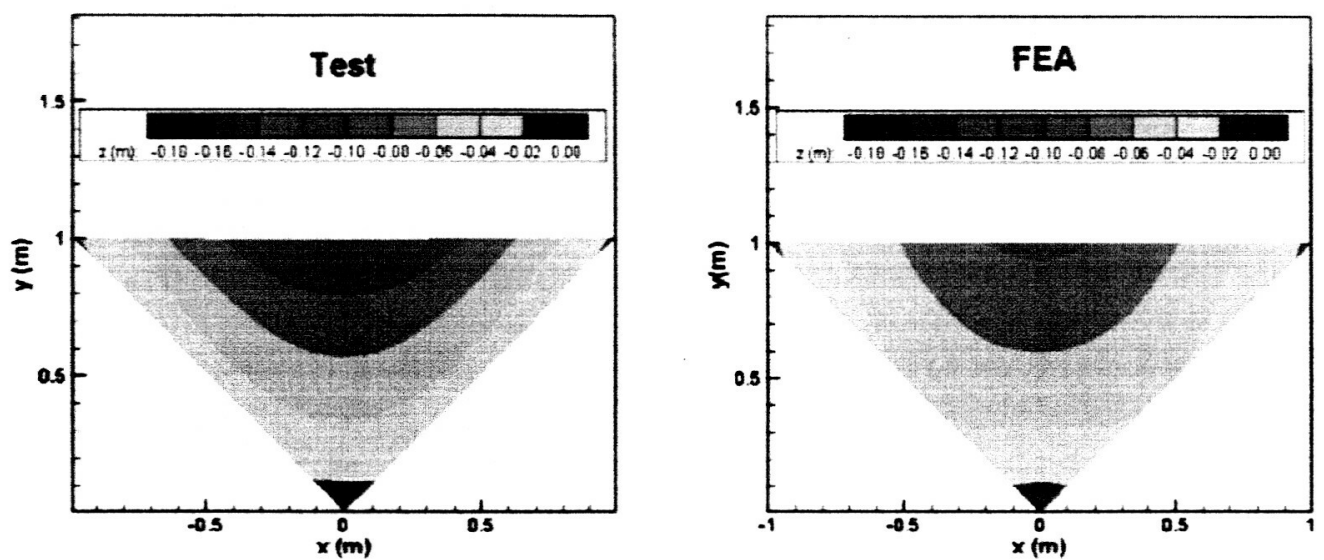

(b) Corner preload $=1.47 \mathrm{~N}$ (150 g masses)
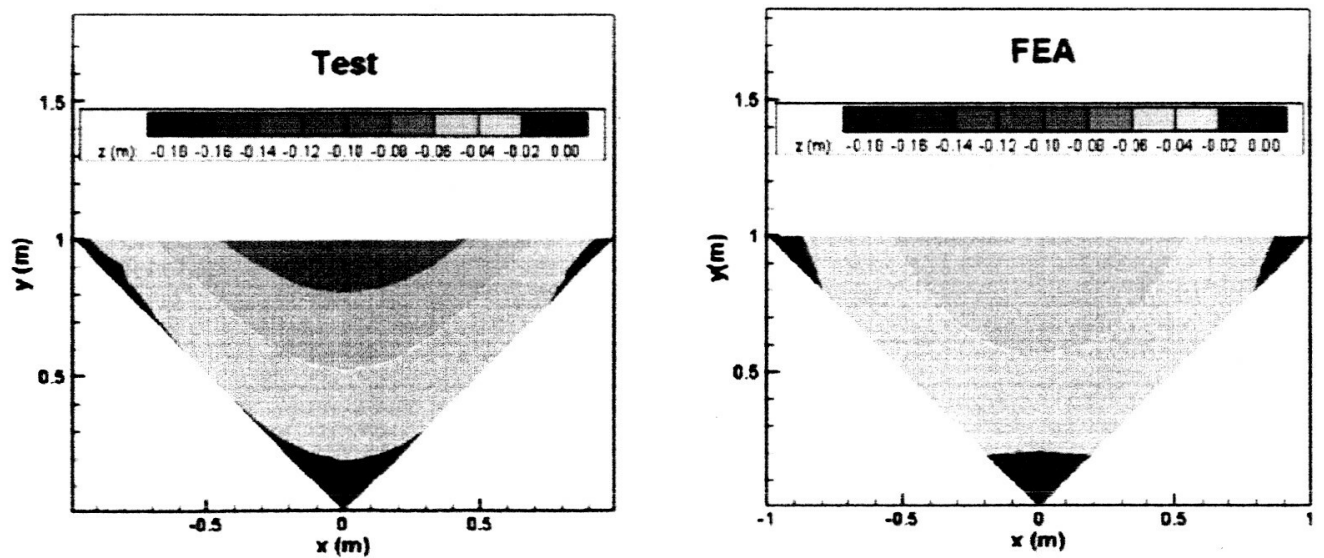

(c) Corner preload $=2.16 \mathrm{~N}$ (220 g masses)

Figure 7: Comparison of measured (Test) and predicted (FEA) out-of-plane (z-direction) displacements in solar sail quadrant orientated horizontally. 

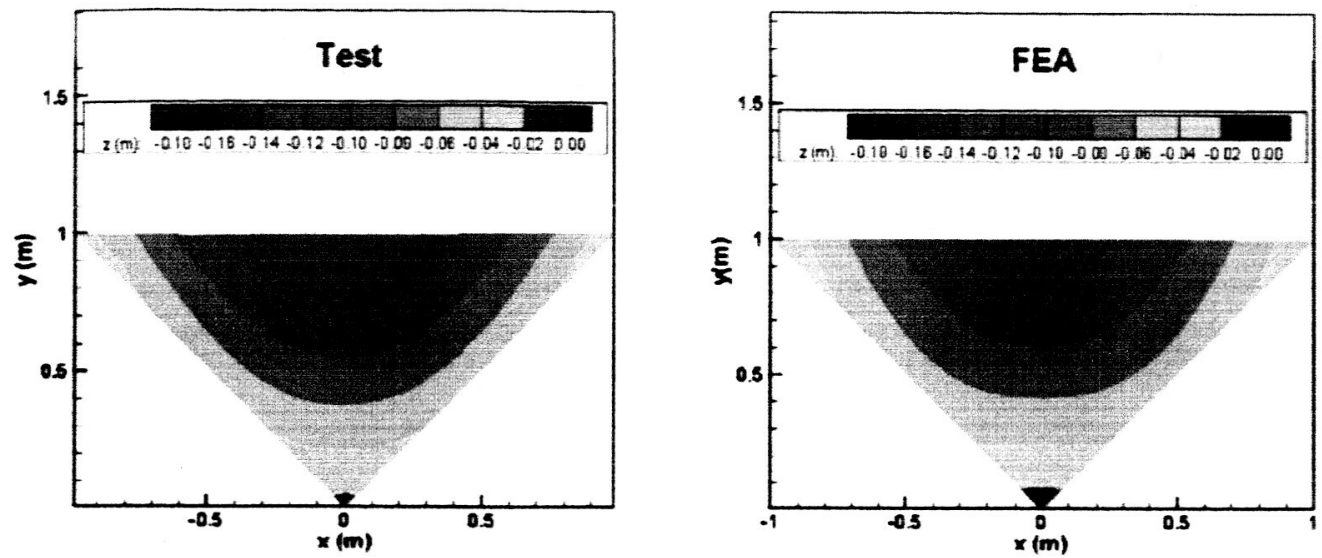

(a) Corner preload $=0.69 \mathrm{~N}$ ( $70 \mathrm{~g}$ masses)
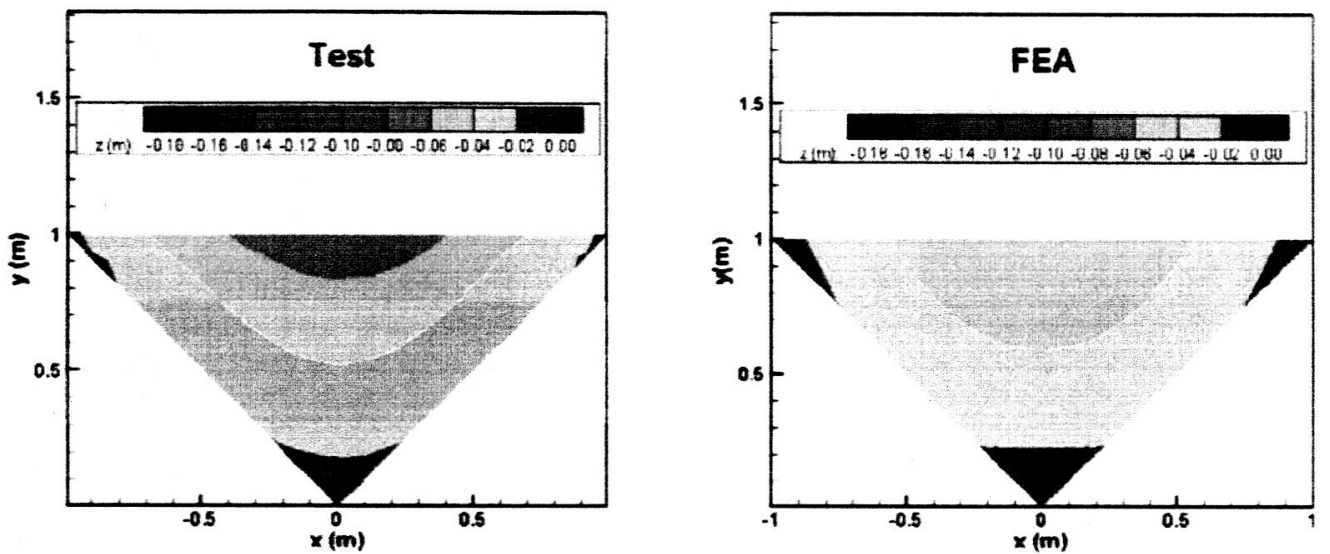

(b) Corner preload $=1.47 \mathrm{~N}(150 \mathrm{~g}$ masses $)$
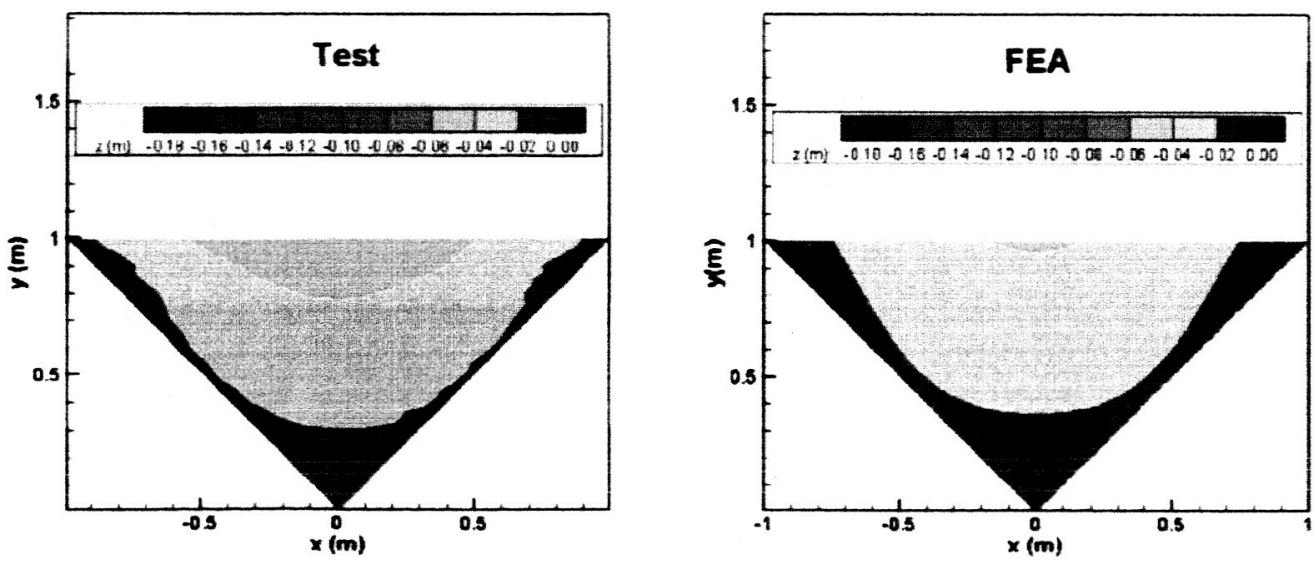

(c) Corner preload $=2.16 \mathrm{~N}(220 \mathrm{~g}$ masses $)$

Figure 8: Comparison of measured (Test) and predicted (FEA) out-of-plane (z-direction) displacements in solar sail quadrant orientated $\mathbf{4 5}$ degrees to horizontal. 

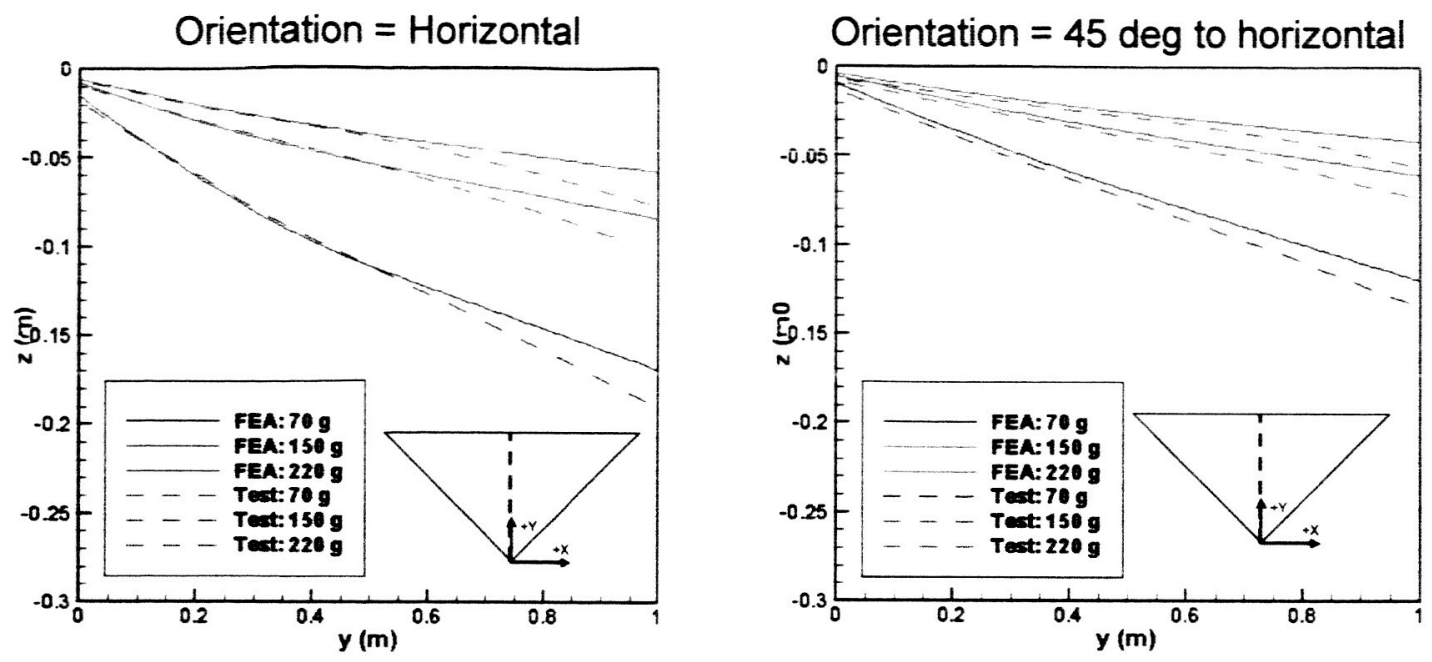

(a) centerline
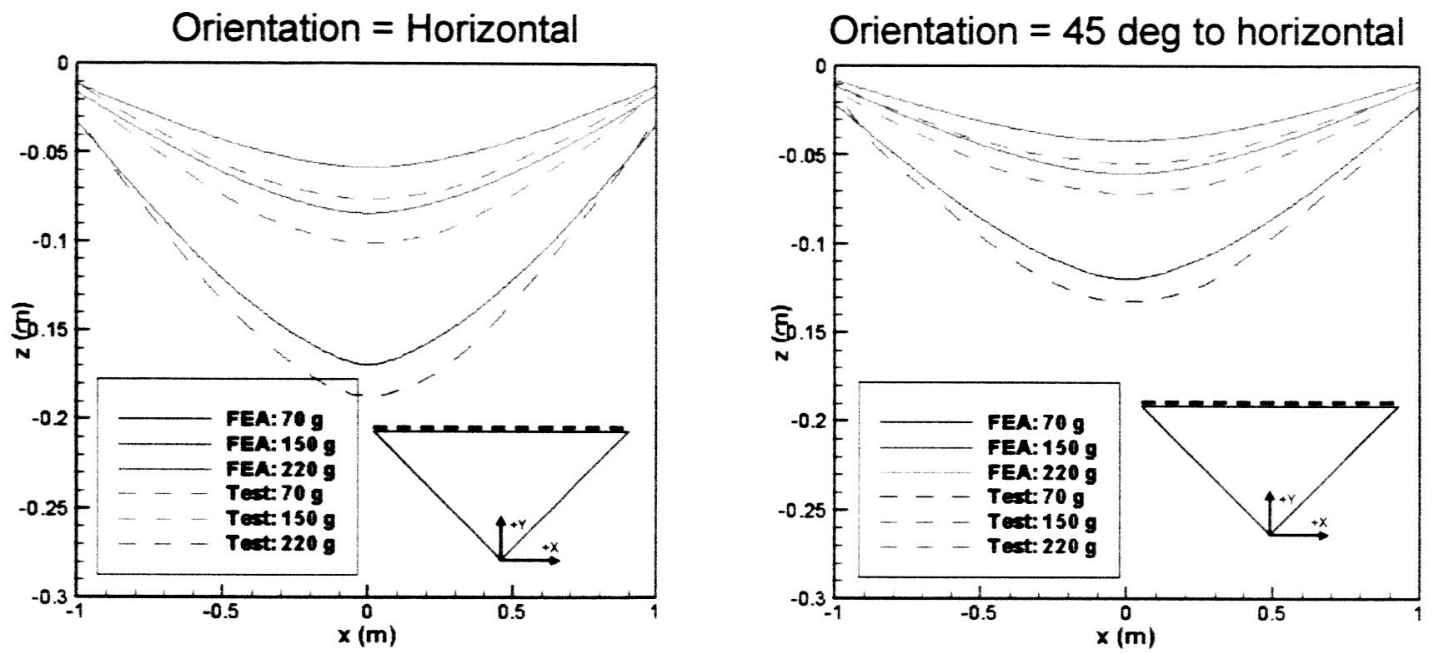

(b) +y edge
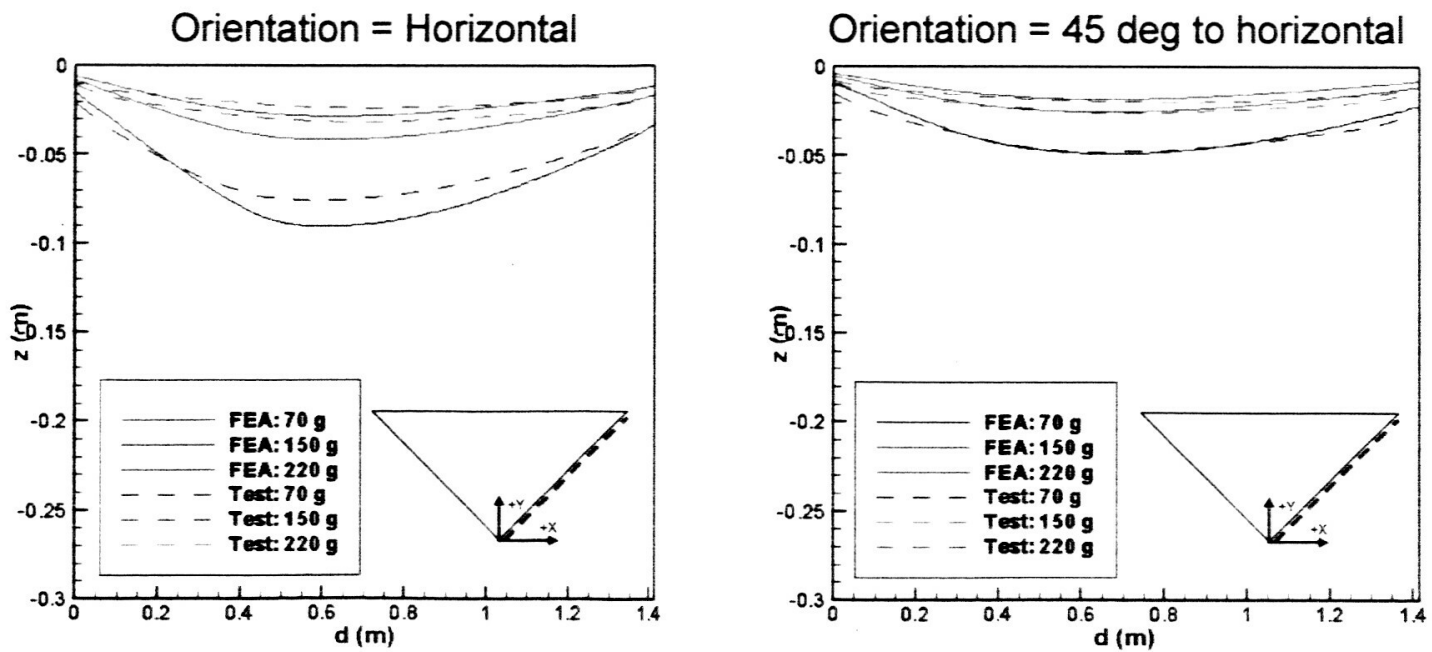

(c) $+x$ edge

Figure 9: Comparison of predicted (FEA) and measured (Test) out-of-plane (z-direction) displacements in solar sail auadrant. 

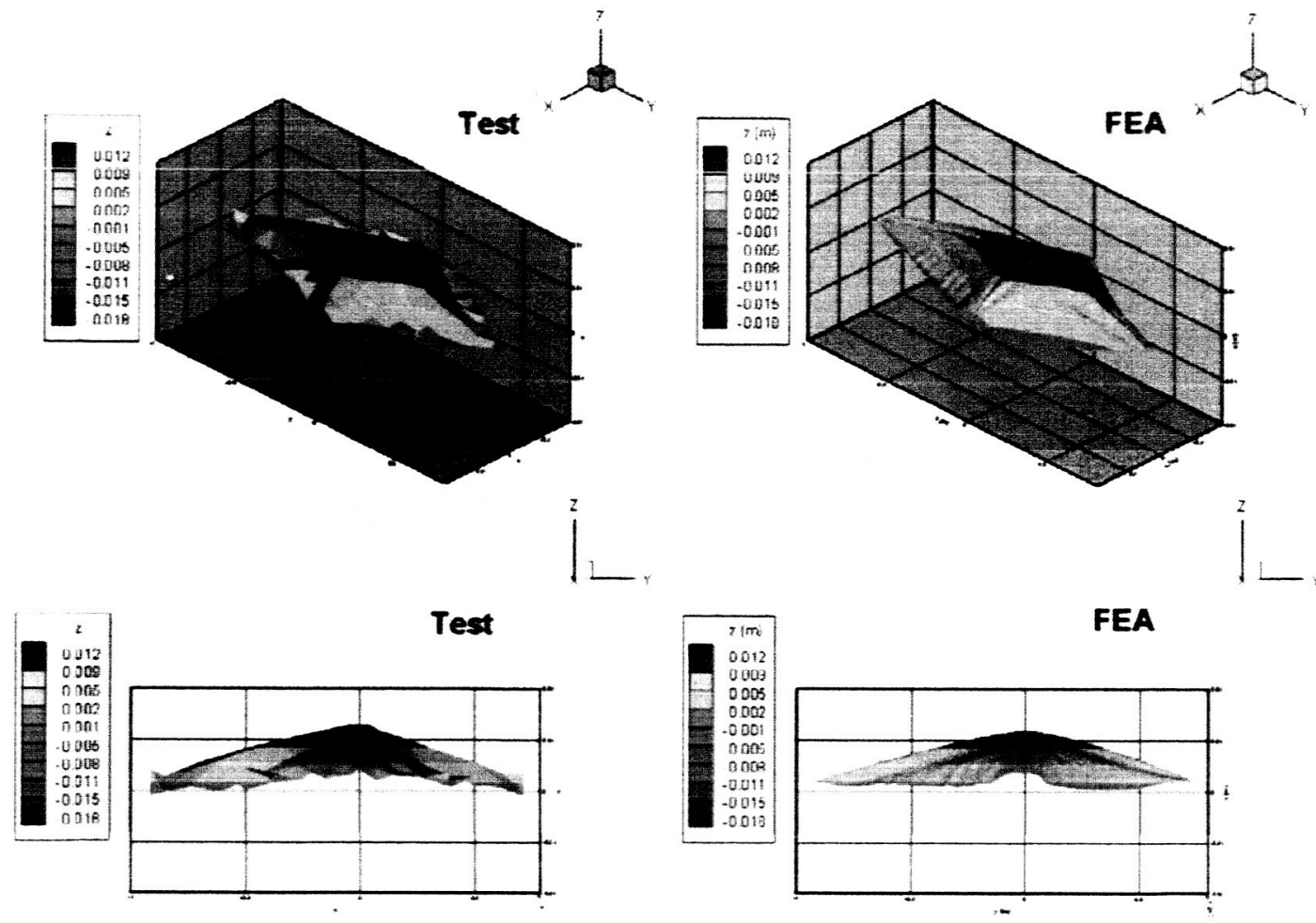

Figure 10: Comparison of measured (Test) and predicted (FEA) surface profiles for sunshield layer orientated vertically under $0.69 \mathrm{~N}(70 \mathrm{~g})$ preload.
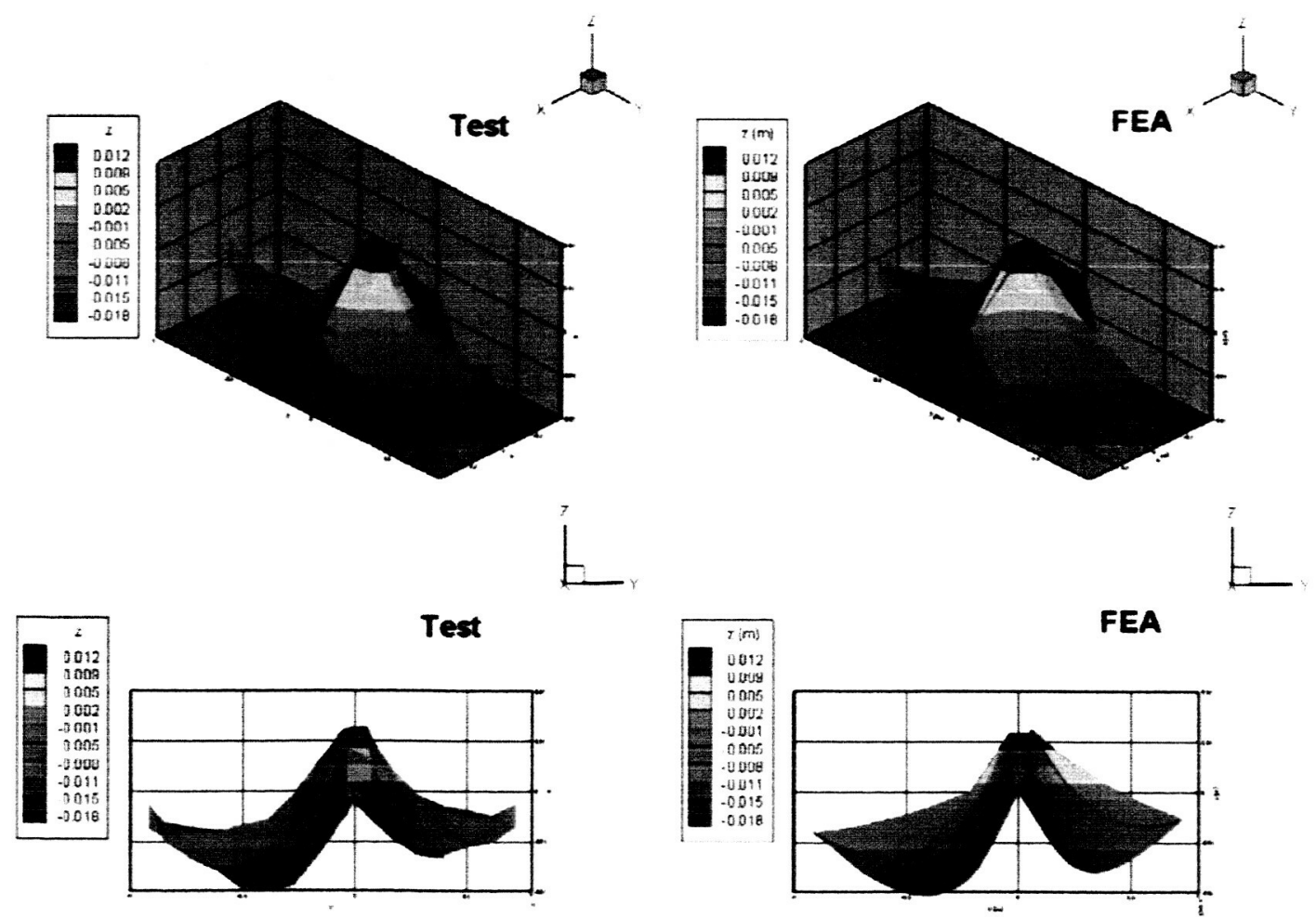

Figure 11: Comparison of measured (Test) and predicted (FEA) surface profiles for sunshield layer orientated horizontally under $0.69 \mathrm{~N}(70 \mathrm{~g})$ preload. 

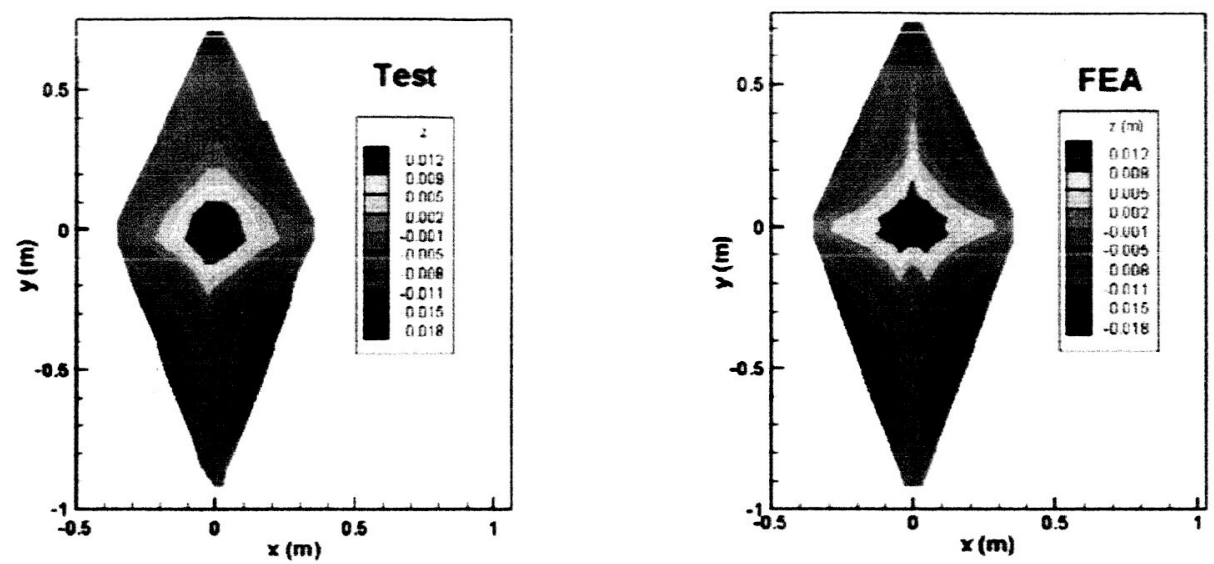

(a) Corner preload $=0.69 \mathrm{~N}$ (70 g masses)
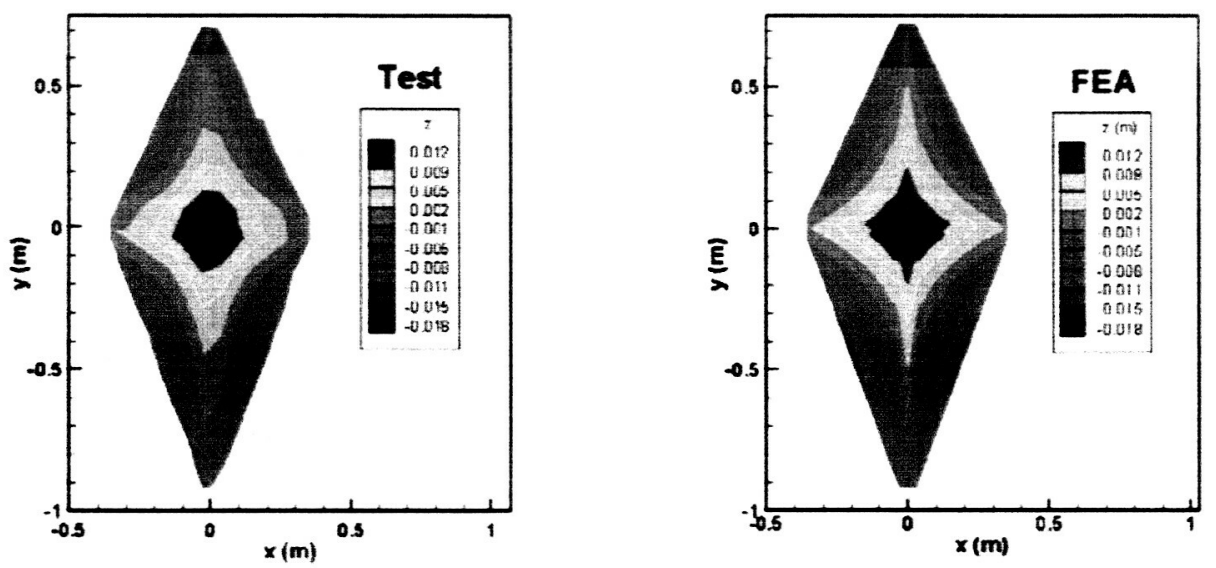

(b) Corner preload $=1.47 \mathrm{~N}(150 \mathrm{~g}$ masses $)$
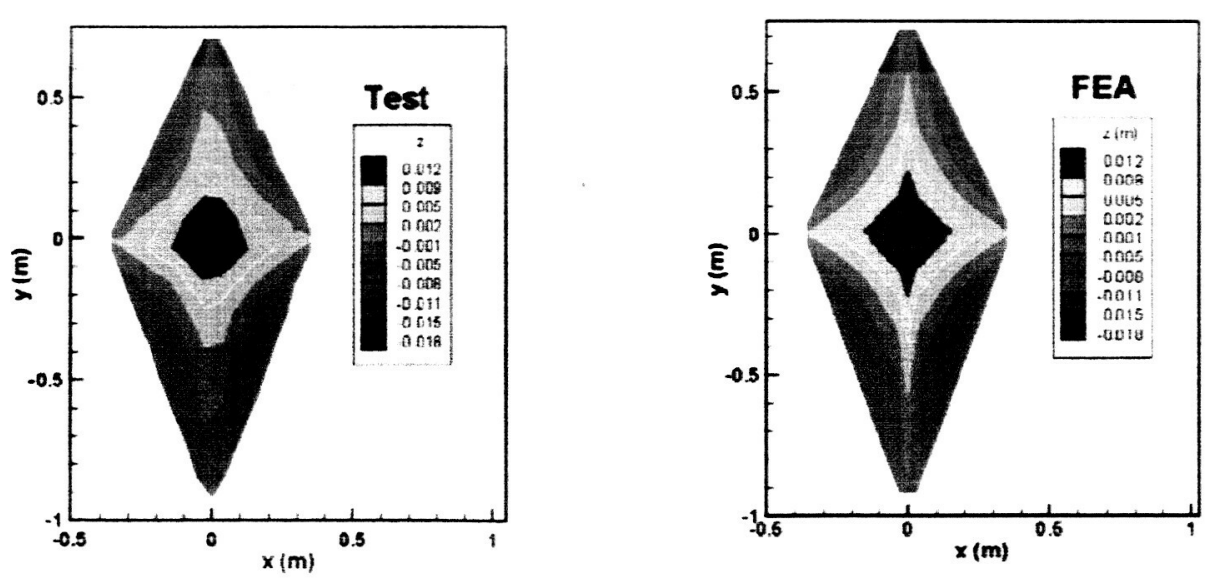

(c) Corner preload $=2.16 \mathrm{~N}(220 \mathrm{~g}$ masses $)$

Figure 12: Comparison of measured (Test) and predicted (FEA) out-of-plane (z-direction) displacements in sunshield membrane orientated horizontally. 


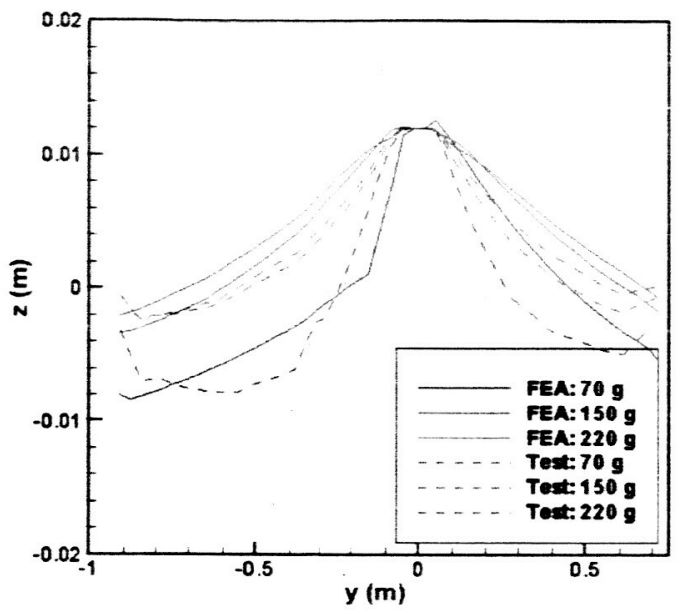

(a) $\mathrm{X}=\mathbf{0 . 0 \mathrm { m }}$

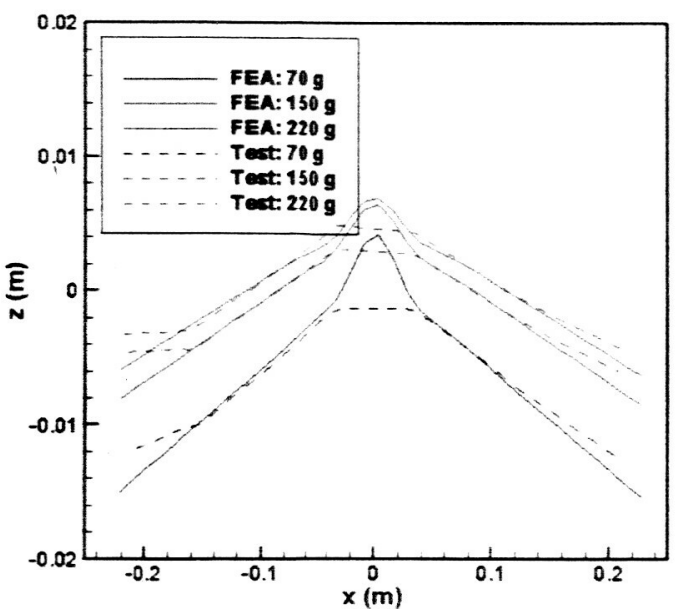

(b) $\mathrm{Y}=+0.3 \mathrm{~m}$

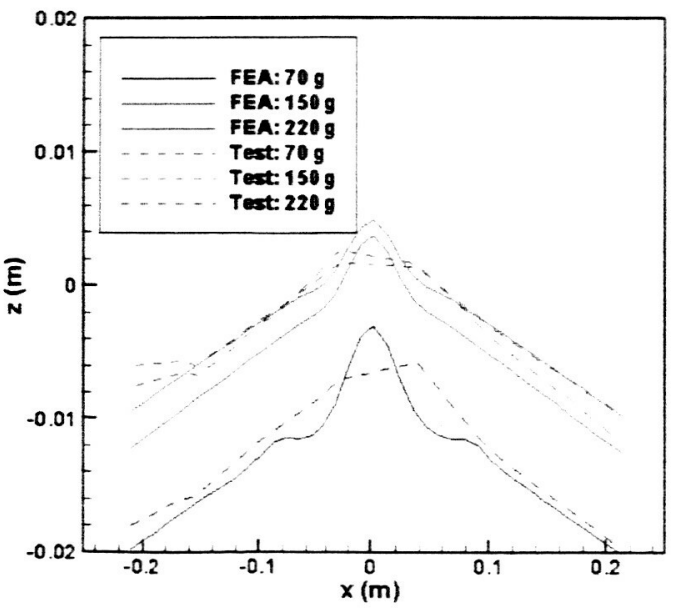

(c) $Y=-0.4 \mathrm{~m}$

Figure 13: Comparison of predicted (FEA) and measured (Test) out-of-plane (z-direction) displacements in sunshieid membrane orientated horizontally. 